\title{
COVID-19: Science, Politics, Media, and the Public-A Systemic View
}

\author{
Felix Tretter $^{1}$ \\ Bertalanffy Center for the Study of Systems Science, Vienna, Austria \\ Angela Franz-Balsen \\ Deutsche Gesellschaft für Humanökologie, Berlin, Germany
}

\section{Abstract}

The COVID-19 pandemic is taken as an opportunity to analyze the role and performance of medical science, the political acceptance of scientific advice, and the importance of mass media as the intermediate link in the "information supply chain." We demonstrate the confusion about indicators of the "dangerousness of the virus SARS-Cov2" by number of deaths. The elective use of one of various possible indicators implies different assessments of risk and, in consequence, different public health measures.

Results and discussion show that COVID-19 pandemic management uncovered the lack of inter- and transdisciplinary culture in medicine and public health, as well as the lack of a conceptual framework. In a systemic human ecological view the framework would be expanded, including the link between ecology and medicine. A perspective of a "human ecology of health" (EHO, 2020) could improve multidimensional understanding of the pandemic and enable connections to other systemic approaches and to sustainability research.

Keywords: corona crisis, public health, medical knowledge integration, systemic ecology of health

\section{Introduction}

COVID-19 is basically a zoonotic disease, as SARS-CoV-2 (severe acute respiratory syndrome coronavirus 2, the virus that causes COVID-19) stems from natural ecosystems that obviously have been overexploited by the human sphere (Cazzolla Gatti, 2020). In this view, the COVID-19 crisis is essentially a human ecological problem (Tretter et al., 2020). Right now, these ecological aspects of COVID-19 are superseded by the medical discourse, al though many experts from different disciplines

1 Corresponding author: felix.tretter@bsss.org. 
have warned of pandemics induced by viruses for years (Morse et al., 2012). For this reason, the conceptual integration of medical and ecological aspects is discussed here with focus on medical science and media-based communication. The COVID-19 pandemic shows the relevance of medicine and science in general as guidance for politics, an issue that has frequently been discussed regarding environmental climate policies ("evidence-based politics"). Currently, societal legitimization and responsibility of science is extremely prominent, as during this pandemic political decisions are based on medical advice, even though scientists-being confronted with an unknown, highly "virtual," and invisible new phenomenon-were not able to offer certainties on how to understand COVID-19 and control the pandemic appropriately. Coping with uncertainty is an essential element of managing disturbances, and was one of the major challenges in COVID-19 management at all levels.

Guidelines for action are rooted in (medical) science, and this medical knowledge is processed by politics and presented by mass media to the public. Finally, it is used to orient people's behavior. This "information supply chain" is rooted in medical science and should be consistent, comprehensive, integrative, and sufficiently coherent in order to enable preventive health behavior of the population (distancing, maskwearing, etc.). Searching for verified information was a key issue, especially as the World Health Organization has described an "infodemic" as a second pathogenic level of the disease: "an overabundance of information, both online and offline. It includes accurate information as well as mis- and disinformation" (WHO, 2020c; see also WHO, 2020b; UNESCO, 2020).

In addition, the COVID-19 pandemic and its management not only coincides with the climate crisis, it also enhances risks for a new economic and financial crisis, enforces the migration crisis, etc. This extensive spectrum of effects of the pandemic demands a broad scope of integrated scientific knowledge in order to foster evidencebased and rational politics. As medical science plays a central role in handling the pandemic, some hidden questions of philosophy of science pop up (Bunge, 1998; Solomon, 2015): Who knows the truth and the appropriate answers to the various societal COVID-19 challenges? Are medical sciences (and their "auxiliary sciences") valid enough? Are the side effects of public health measures on the economy, human rights, etc. considered appropriately?

The so-called medialization of science (Heckl, 2020; Peters et al., 2008) was a necessary step in the information supply chain. Medialization of politics and of science were in fact parallel processes during the pandemic: both politics and medical science/public health needed the fast and far-reaching channels of mass media to have daily or even hourly access to the public. Media and journalists all over the world have responded as a means of science communication, health communication, and risk communication (Arinze-Umobi \& Chiweta-Oduah, 2020; Balarabe, 2020) and sometimes — where freedom of press is guaranteed—as critical 
commentators of national political decision-making (UNESCO, 2020). These processes confirm the sociological view of societies being essentially communication systems (Luhmann, 1984/2012).

Here, we try to touch on some of the manifold challenges a knowledge society has to meet in order to guarantee a well-functioning information supply chain on the pandemic. The central example in our study is the risk of death (mortality/fatality rates) from COVID-19.

\section{Methods}

Focusing on the communicative aspects of crisis management, we present a rough sketch by a selective, comparative, and qualitative assessment of perception, evaluation, and management of the COVID-19 pandemic. We focus on Europe and on the spring period (from March 1 to May 25, 2020) because during summer (June till August) a second period occurred due to travelling activities. Again, internationally varying lockdowns and border closures were ordered. In fall 2020 (the third period), most European countries exhibited nearly the same national intensity of the epidemic as in spring.

The available data for empirical research is soft, because of severe differences in indication of testing, as well as in the time elapsed between taking samples and reporting test results to the subjects, to the local authorities, and to federal institutions. Finally, the time of day of reporting-8 AM, 2 PM, or 5 PM-changed over time, resulting in differences of reported numbers in international dashboards. For instance, the Robert Koch Institute in Germany had to revise published data several times and had to admit intrinsic variations of daily reported new infected cases and finally decided to report in "nowcasting mode," which estimates the "real" point of time when the tests were positive (RKI, 2020a). This is important for calculation of the reproduction number $\mathrm{R}_{\mathrm{eff}}$, which indicates the number of individuals infected by one infected individual. This kind of careful data management is not practiced in all other countries. For this reason, and because we only aim at an exploratory study, we do not use official higher order databases, as provided by the European Union or WHO. All those secondary databases might suffer from these failures of primary data acquisition. In consequence, the number of new infected per day can differ by around $+/-10$ percent between reporting institutions, but not in the range of multiples of the reference value. For convenience we used the "dashboard" of country data available at Worldometer (Worldometer, 2020), after cross-checking it with other dashboards (AGES, 2020; RKI, 2020b; WHO, 2020a). For our comparison, we selected European countries with widely differing medical advice and management strategies regarding public health and public order measures: Austria (A) and Germany (GER) vs. Sweden (S) and United Kingdom (UK). 
We also analyzed reports from the scientific community, examples of mass media reporting, and examples of journalists' inner professional discourses (see websites of e.g., Science Media Centre, UK; DJU (Deutsche Journalisten Union); WPK (Die Wissenschaftsjournalisten), Medien Doktor Gesundheit) in order to describe the challenges and problems of credible and verified data communication towards decision-makers and the public. Focus of our analysis is the meaning of "dangerousness" of the virus, measured by the risk of death if infected.

\section{Results}

Basically, we see severe conceptual differences, terminological fallacies, and methodological diversities (e.g., laboratory view of virology and data-centered view of epidemiology) that undermine "intradisciplinary" and in consequence also "extradisciplinary" 2 medical communication to other societal fields.

\section{1) Lack of integration across medicine as a discipline}

Medicine as a diversified academic discipline (virology, epidemiology, hygiene, internal medicine, immunology, etc.) lacks intradisciplinary integration (Tretter \& Löffler-Stastka, 2019a). The resulting inconsistencies in evaluating the pandemic cannot be resolved by mass media (see below, "two experts, two opinions") and in consequence the public trust in medicine could decline. The following weaknesses are sources of contradictory statements:

- Underestimation of clinical experience: according to evidence-based medicine, clinical experience is heavily underestimated. In case of COVID-19, randomized controlled studies — especially regarding public health affairs — are not possible. More casuistic reports would have helped to understand the health risk of COVID-19 and to dampen the dynamics of the pandemic.

- The dominance of abstract information by virology (molecular biology) and epidemiology (mathematics, statistics) over concrete information by internal medicine and the consecutive neglect of the pathophysiological mechanisms of symptoms of COVID-19 (from nose to lungs) corresponds essentially with the absence of a theoretical medicine that could explain the severe pathological conditions of the disease (Figure 1). Currently medicine favors "dataism" as everything appears rational as long as "numbers" are presented, even if it is hard to interpret them conceptually.

2 Extradisciplinary means one-directional messaging to politics and public, therefore we don't use the term "transdisciplinary." 


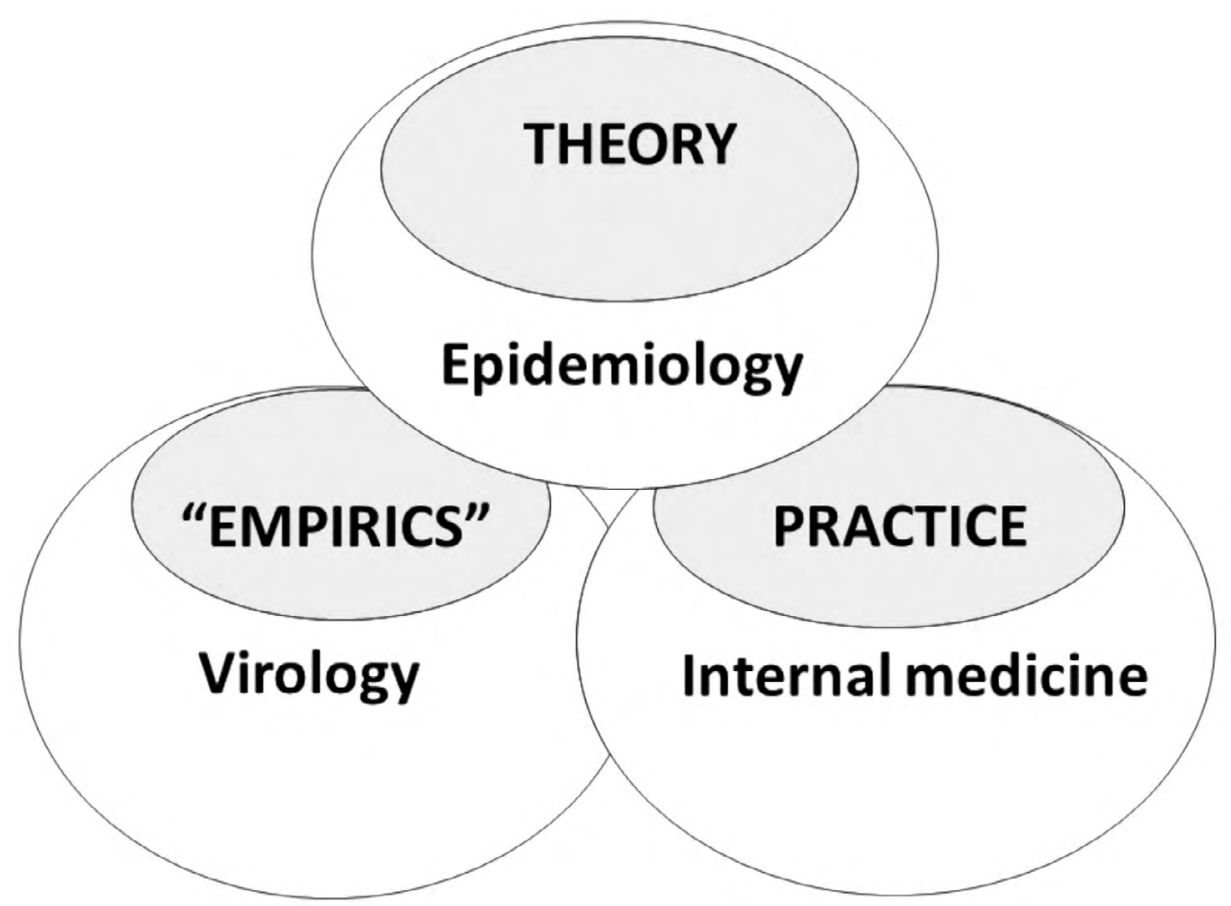

Figure 1. Dominant and marginalized COVID-19 discourses.

Note: Virology and epidemiology dominate the internal and external COVID-19-related discourse with a neglect of practical medicine, represented in this graphic by the field of internal medicine. Theoretically, only the integrated view of these specialties of medicine could provide a balanced picture of the COVID-19 problem. "Empirics" subsumes experimental, field, and statistical research.

Source: Authors' representation.

\section{2) Inaccuracies of language}

The different medical subdisciplines obviously implicate preferences for different categories to characterize the risk of death. Epidemiologists might prefer the concept of "mortality" (deaths/100,000 inhabitants) as mortality helps to indicate the general comparative risk of death. For instance, for Germany and Austria, the mortality of COVID-19 is about $0.1 \%$. $^{3}$ Other medical experts (e.g., virologists) prefer the "case fatality rate" for deceased persons who were tested positively, which results in a 400-times larger number, namely 4 percent. Infectiologists often use the "infected fatality rate," which is calculated by serological antibody ratio in representative samples. These different numbers are not used correctly within medicine, as became public when medical experts discussed mortality risk (see below). By fall 2020, public opinion in Germany and Austria (and obviously in other countries too) had become widely polarized regarding the "dangerousness" of SARS-CoV-2.

3 At time of writing, October 2020. 
These differences of indicators imply the necessity for consensus and consistency conferences in medicine (and for the public) about the appropriate choice of indicator. The societal relevance of this difference, especially in context of politics, is that the mortality number is calming the public, whereas lethality number induces anxieties, as will be discussed in more detail later.

\section{3) Fuzziness of virological and epidemiological measurements}

These terminological issues are closely related to the quality of testing, such as number of diagnostic tests being applied (correlation between percentage of tested population and percentage of test-positives), the indication of testing (symptom carrier or coming from a "hot spot"), quality of the tests (validity, reliability, specificity, etc.), and the temporal contingency of measurement and presentation of the data to politics (variable time delays). All these factors attenuate the power of evidence of epidemiological research. In consequence, the strength of empirical evidence of dynamics of national epidemics is relatively weak.

\section{4) Overevaluated data analytics and models for forecasting}

This complex methodological fuzziness of data acquisition implicates severe restrictions in data analysis, although these data are used for forecasting of future development of the pandemic and for assessment of public health measures. Simple epidemiological indicators such as doubling interval or reproduction number, indicating the number of individuals infected by one infected individual $\left(\mathrm{R}_{\text {eff }}\right)$, are only appropriate in brief phases of exponential development of the epidemicl pandemic. In consequence, predictive modeling of the development of the pandemic is mathematical extrapolation and simulation with increasing error probability (Ioannidis et al., in press).

Regardless of these methodological restrictions, some politicians did use the primary scientific information in a wrong way (e.g., without presentation of the "prediction interval" of forecasts), and maybe even intentionally to induce collective anxieties ("There will be 100,000 deaths (in Austria)"; Bartlau, 2020). This was directly communicated by mass media to the public. By this kind of uncritical information transfer, the credibility of science could suffer. Whenever such predictions do not eventuate in reality, public trust in science could decrease-as we already see by the growing number of COVID-deniers. 
This increasing public distrust, however, is also partially rooted in the diversity of medical specialities that present their results and recommendations to the public without a common reference frame. In particular, the subjective situation of the people as "situated subjects" is overseen, as humans should be seen in their ecological and social context (Dreier, 2020; Tretter, 2008). Interestingly, WHO, in a recent publication, recognized pandemic fatigue and recommends human-centered and community-based interventions (WHO, 2020d).

\section{5) Lack of valid studies into pandemic interventions}

The assessment of the control of dynamics of the COVID-19 pandemic still lacks valid studies that clearly identify which intervention strategies successfully dampened the pandemic.

It is hard to define differences that make a difference. For a while, the effective reproduction number $\left(\mathrm{R}_{\mathrm{eff}}\right)$ was used to characterize the dynamics of the pandemic. This was communicated to the public. But it turned out that many assumptions underlying this indicator (e.g., estimation of latency between infection and symptoms that lead to testing, maximum of spreading of the virus, etc.) diminish its validity, and more indicators must be used for this purpose. For example, by mid-March, a significant starting point of the pandemic in Europe, some politicians (e.g., UK Prime Minister Boris Johnson) followed scientists (e.g., Sir Patrick Vallance-a pharmacologist, not a virologist, not an epidemiologist) who emphasized "herd immunity," aiming at an infection rate of 60 percent of the population in order to attenuate the dynamics of the epidemic. In consequence, the UK applied only "soft" hygiene measures (e.g., recommendations for distancing) and only at the end of March was lockdown ordered. Boris Johnson, on March 27, tested positive to the virus and after four weeks of illness, including a hospital stay, came back to office on April 28. His personal affectedness changed general COVID-19 assessment in the UK. Obviously too late, as the UK had an extremely high number of infected until summer 2020 and-compared to Germany-also a very high death rate. This is also true for Sweden, if we compare it with Austria, a country with a hard lockdown (e.g., obligatory distancing) and about the same number of inhabitants (see Table 1). Depending on the figure used — such as mortality or case fatalitythese differences can be higher or lower. This could be abused for political aims, for instance to criticize hard lockdown policies by their lower impacts on the case fatality rate (CFR) compared with mortality reduction. 
Table 1. Country-related epidemiological indicators of COVID-19.

\begin{tabular}{|l|c|c|c|c|c|}
\hline Date: May 25, 2020 & $\begin{array}{c}\text { Tests/Million } \\
\text { inhabitants }\end{array}$ & $\begin{array}{c}\text { Cases/Million } \\
\text { inhabitants }\end{array}$ & $\begin{array}{c}\text { Cases/ } \\
\text { Tests }\end{array}$ & $\begin{array}{c}\text { Deaths/Million } \\
\text { inhabitants }\end{array}$ & $\begin{array}{c}\text { Deaths/ } \\
\text { Cases }\end{array}$ \\
\hline Germany (GER) & $\begin{array}{c}42,923 \\
(0.4 \%)\end{array}$ & $\begin{array}{c}2,153 \\
(0.2 \%)\end{array}$ & $5 \%$ & $\begin{array}{c}100 \\
(0.01 \%)\end{array}$ & $5 \%$ \\
\hline United Kingdom (UK) & $\begin{array}{l}50,979 \\
(0.5 \%)\end{array}$ & $\begin{array}{c}\mathbf{3 , 8 2 5} \\
\mathbf{( 0 . 4 \% )}\end{array}$ & $7 \%$ & $\begin{array}{c}\mathbf{5 4 2} \\
\mathbf{( 0 . 0 5 \% )}\end{array}$ & $14 \%$ \\
\hline Austria (A) & $\begin{array}{l}44,645 \\
(0.4 \%)\end{array}$ & $\begin{array}{c}1,839 \\
(0.2 \%)\end{array}$ & $4 \%$ & 71 & $3 \%$ \\
\hline Sweden (S) & $\begin{array}{l}29,797 \\
(0.3 \%)\end{array}$ & $\begin{array}{c}\mathbf{3 , 3 1 3} \\
\mathbf{( 0 . 3 \% )}\end{array}$ & $11 \%$ & $\mathbf{3 9 6}$ & $12 \%$ \\
\hline
\end{tabular}

Soft lockdown (UK, S) is accompanied with doubling of population-based rate of infected (bold numbers) and with a 5- to 6-fold higher rate of deaths compared to countries with hard lockdown (GER, A). If deaths/cases (CFR) are used as indicators the difference is only 3- to 4-times higher.

Source: Worldometer (2020) and (rounded) calculations by authors.

\section{Role of media in the information supply chain}

In regard to the information flow, the next step following after science is mass media. Their output in spring 2020 mirrored the above-mentioned inconsistencies of medicine.

Mass media had to inform the public about the nature of the virus and its dangerousness (science communication, risk communication), had to disseminate hygiene measures (health communication), and had to report on the sociopolitical dimension of the pandemic (core of traditional, political journalism). Science itself had difficulties in correctly communicating data and gathering first findings under pressure and uncertainty; media were overstrained as well, especially regarding the data for risk and health communication. Public health authorities or politicians passed on absolute numbers of cases or deaths mixed up with mortality or fatality numbers (see above). During the first wave of the virus, incidents like the following were characteristic:

- May 24, 2020: Austrian TV program Im Zentrum (ORF):

The moderator finds herself between two medical doctors who use different languages: Dr. Montgomery (President of the World Federation of Physicians) talks about the "case fatality rate," while the other expert presents mortality numbers. The numbers they give don't match. The discrepancy ( $4 \%$ vs. $0.2 \%$ ) cannot be clarified by the doctors, so the moderator ends the discussion by stating "two experts, two opinions." 
- 30 March, 2020: Kurier (an Austrian daily newspaper):

Based on experts' calculations and forecasting, the Austrian Government issues a press release that confounds "replication rate" (intracellular replication rate of virus) and "reproduction number R" (the number of susceptible persons being infected by a single infected person). Journalists don't question the authority of scientists and Chancellor, and copy the mistake. ${ }^{4}$

The blame for such confusions was mainly attributed to the media by the medical sector (e.g., EbM Netzwerk, 2020). Over time, an intensive learning process in health and risk communication can be observed, especially regarding data management in mass media. Self-reflective articles on ethics and the responsibility of journalists in the face of COVID-19 are to be found on the discussions of professional associations $^{5}$ or broadcast stations. ${ }^{6}$ Tool boxes (e.g., glossary of epidemiological terminology) are offered also by public health institutions (Wegwarth et al., 2020; WHO 2020b, 2020c).

Media now recommend visiting their online services, where ambiguity of data can be better explained; they turn to weekly reporting, commenting on validity of data, and explaining their choice of terms and parameters. This seems highly acknowledged by the audience. An example from the UK, where government policies were not transparent and scientific advice arbitrary (see above), is the rise of The Guardian from a minority paper to the most trusted source of information in the UK. There has been an increase of website visitors from 191 million in February 2020 to 366 million in March, with 2.17 billion page views in March 2020 (UNESCO, 2020).

In summary, the results from some European lead media show that they tried hard to deliver responsible journalism, based on verified data, as some media researchers attest (Boberg et al., 2020). But media professionals were also not free from flaws: the shock/impact of the first wave of the pandemic influenced their choice of subjects and style of reporting. A study on German special TV documentaries on COVID-19 shows that critical comments on policies of crisis management were missing, while iteration of gloomy descriptions of the crisis fostered the social construction of crisis (Gräf \& Hennig, 2020). Further and comparative studies are needed to elicit how the media complied with their extremely important role as mediators between science, politics, and public.

\footnotetext{
4 kurier.at/wissen/gesundheit/coronavirus-prognose-deutlich-strengere-massnahmen-notwendig/400796975.

5 For example: Science Media Centre, UK (www.sciencemediacentre.org); DJU (Deutsche Journalisten Union); WPK (Die Wissenschaftsjournalisten); Medien Doktor Gesundheit.

6 For example: Deutsche Welle: www.dw.com/en/data-journalism-in-times-of-coronavirus/a-54116323.
} 


\section{Discussion}

Methodological and epistemological diversification of medicine implies a loss of conceptual and theoretical integration (the relationship between "empirics" and theory). Also, the conceptual weakness of medicine uncovered by COVID-19 pandemic is an intrinsic problem of hyper-diversification of medical specialties. In consequence, this diversity of medical viewpoints on the COVID-19 pandemic seem to create contradictions, which can be enforced in the information supply chain by mass media. These contradictions might result in splitting of public opinion. Obviously, in this discourse "the limits of my language mean the limits of the world" (Wittgenstein, 1921/1981). This situation shows the need for an integrative conceptual framework, such as an integrative ecological "systems medicine" that considers health and disease top-down from the whole, situated person (Tretter $\&$ Löffler-Stastka, 2019b).

In addition, COVID-19 shows that medicine has to be able to communicate with other disciplines - for instance, with economics. Regarding the wide societal consequences of COVID-19, an even wider scientific framework seems to be useful to ensure comprehensive "evidence-based" policies.

\section{The human ecology perspective: A "big picture" of COVID-19}

In order to connect these different academic perspectives in an integrative conceptual framework, we suggest using a systemic socioecological feedback template (Dyball $\&$ Newell, 2015). This approach might be useful to relativize some controversies. It captures the interconnections between the ecosystem, human well-being, societal institutions, and cultural paradigms. This template is useful for a broader view of social ecological systems in general (Figure 2A). For the purposes of framing the "big picture" of COVID-19, we map the variables to those more specific to this pandemic (Figure 2B). This application of the template summarizes most of the points we have discussed. They will be elaborated in more detail (Tretter \& Reichel, 2020), but serve well here to represent the main functional structure of the COVID-19 system, as follows.

The human community manipulates natural ecosystems to yield resources that it values (activities and processes, represented by link 1). Unintentionally, these manipulated ecosystems also create conditions favoring the evolution and flourishing of pathogenic viruses that impair human health, leading infected human individuals to infect other humans (pathways transmitting the virus are represented in link 2). Medical reports on empirical evidence of the health status of the population stimulate discussions in politics, mass media, and public opinion that push for a new societal concern to take the pandemic seriously, which comes to constitute a new paradigm. 
(The process of observing and learning about the pandemic and the pressure for a change in dominant values are captured in link 3.) Whether the dominant paradigm does change depends on the relative strength of concerns prioritizing health over counterarguments that prioritize the strength of the economy. This "new normality" is institutionalized by measures for public health and public order like distancing, use of masks, etc. (The process of generating these guidelines and behavioral rules is represented by link 4). These rules and norms of behavior directly change the state of human well-being, through activities such as limited group sizes, reduced handshaking, and increased mask-wearing (activities represented by link 5), creating conditions less conducive to the spread of the virus, as measured by reduction in epidemiological indicators. Observations of the success of the behavioral change further reinforce the new emerging "health first" cultural paradigm (learning processes represented by link $3^{\prime}$ ). In turn, this paradigm is also influenced by the perception of the value of levels of institutionalized regulations (a process of formally and informally reviewing policies represented by link 6). This perception might result in, for example, a reduction of lockdown measures, if it was judged that the regulations were unnecessarily restrictive, or creating countervailing indicators of harms to well-being, such as depression or domestic violence (the process of creating new, more relaxed guidelines is represented by link $4^{\prime}$ ). In the long run, even the collectively perceived health risks of interpenetration of human systems with natural ecosystems (i.e., zoonoses) might change the priorities of the cultural paradigm of unlimited use of ecosystems (process of reevaluation represented by link 7). In time, this could lead to new collective behaviors (represented in link $1^{\prime}$ ) that do not create novel ecosystem niches conducive to zoonotic crossover to humans.
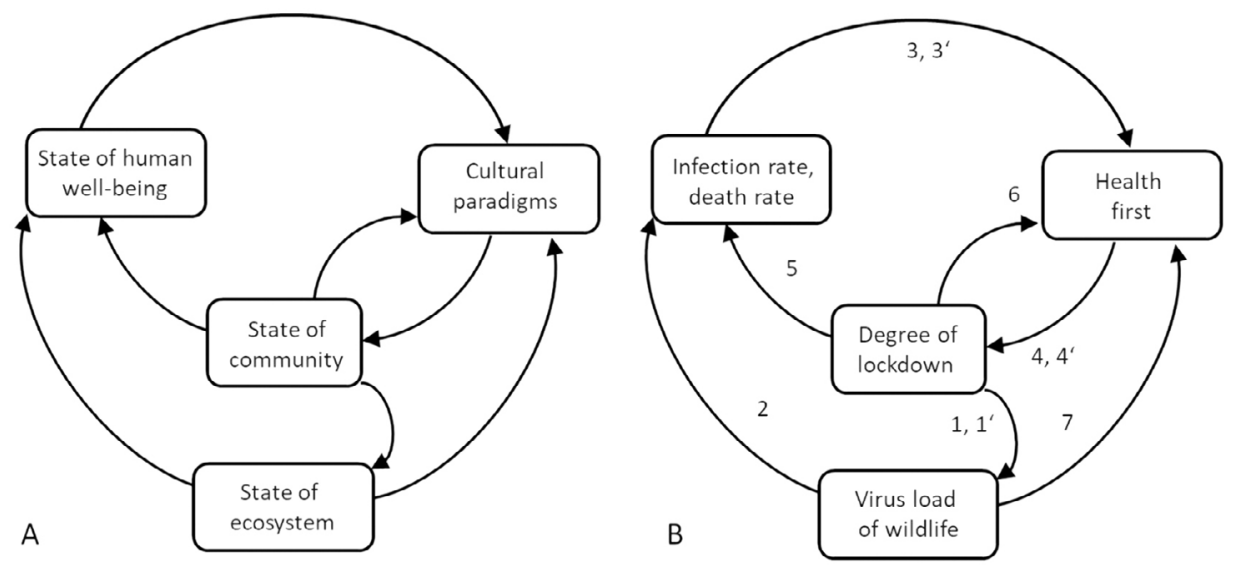

Figure 2. Application of a human ecological framework. The basic template (A) and the adaptation to the "big picture" of COVID-19 (B).

Source: Dyball and Newell (2015). 


\section{Conclusion}

In summary, some evidence is provided that medicine and public health lack intradisciplinary conceptual integration and inter- and transdisciplinary methodological culture. This can be seen in the current medical COVID-19 discourse, which also ignores the valuable conceptual linkages between ecology and medicine. Bridging such gaps might enhance consistency and coherence of medical advice in managing COVID-19 pandemic. In line with this, an elaborated perspective of a "human ecology of health" (EHO, 2020; see also WHO, 2005) could provide a theoretical bridge to other research approaches, such as One Health (see WCS, 2020; WHO, 2017, 2018) and also to sustainability research. This kind of integrative ecological systems medicine is needed to participate in and shape public and political discourses regarding further global crises.

\section{References}

AGES. (2020). COVID-19 dashboard. Österreichische Agentur für Gesundheit und Ernärhungssicherheit (AGES) [(Austrian) Agency for Health and Food Safety]. Retrieved May 5, 2020, from covid19-dashboard.ages.at

Arinze-Umobi, S. O., \& Chiweta-Oduah, O. (2020). COVID-19 crisis response strategies: The place of mass media. International Journal of Advanced Research, 8, 1102-1109. doi.org/10.21474/ijar01/10883

Balarabe, U. B. (2020). Impact of COVID-19 and pandemic lockdown in India: Role of media during lockdown. In A. Shukla (Ed.), Impact of COVID-19 \& pandemic lockdown in India: Ramification in environment and human life (pp. 175-184). Eureka Publications.

Bartlau, C. (2020). Er, nur er allein [He, just him]. ZEIT ONLINE. www.zeit.de/ politik/ausland/2020-04/sebastian-kurz-coronavirus-krisenmanagement-strategie/ komplettansicht

Boberg, S., Quandt, T., Schatto-Eckrodt, T., \& Frischlich, L. (2020). Pandemic news: Facebook pages of mainstream news media and the coronavirus crisis-a computational content analysis. (Münster Online Research (MOR) Working Paper 2/2020). University of Münster. ArXiv. arxiv.org/pdf/2004.02566.pdf

Bunge, M. (1998). Philosophy of science (Vol.2). Routledge. doi.org/10.4324/9781315126371

Cazzolla Gatti, R. (2020). The pangolin's revenge: SARS-CoV-2 did not emerge from a lab but from wildlife exploitation. GAIA, 29(2), 79-82. doi.org/10.14512/gaia.29.2.3

Dreier, O. (2020). Critical psychology: Subjects in situated social practices. In M. Fleer, F. González Rey, \& P. Jones (Eds.), Perspectives in cultural-historical research: Vol. 8. Culturalhistorical and critical psychology. Springer. doi.org/10.1007/978-981-15-2209-3_2 
Dyball, R., \& Newell, B. (2015). Understanding human ecology: A systems approach to sustainability. Earthscan. doi.org/10.4324/9780203109557

EbM Netzwerk. (2020). Risikokommunikation zu COVID-19 in den Medien [Risk communication for COVID-19 in the media]. www.ebm-netzwerk.de/de/veroeffent lichungen/pdf/stn-risikokommunikation-covid19-20200820.pdf

EHO. (2020). Developing the human ecology of health. European Health Organisation. Retrieved August 3, 2020, from www.organisation-europeenne-sante.ch/en

Gräf, D., \& Hennig, M. (2020, September 17). Die Verengung der Welt. Zur medialen Konstruktion Deutschlands unter SARS-CoV-2 und COVID-19 anhand der Formate "ARD Extra-Die Coronalage" und "ZDF Spezial" [The narrowing of the world. The media construction of Germany under SARS-CoV-2 and COVID-19 in the formats of "ARD Extra—the Corona situation" and "ZDF Special"]. Magazin des Graduiertenkollegs Privatheit der Universität Passau, 14(2020), 14-21. issuu.com/grkprivatheitdigitalisierung/ docs/magazin_cov-19_september_2020_issuu/14

Heckl, W. M. (2020). Wissenschaftskommunikation-in Corona und Post-Corona-Zeiten wichtiger denn je [Science communication-more important than ever in Corona and post-Corona times]. In M. Molls, \& J. Eberspächter (Eds.), Wissenschaft, Vernunft, Nachhaltigkeit_Denkanstöße für die Zeit nach Corona [Science, reason, and sustainabilityfood for thought for the time after Corona] (pp. 72-75). Technische Universität München (TUM) Forum Sustainability: TUM Senior Excellence Faculty \& TUM Institute for Advanced Study. mediatum.ub.tum.de/doc/1548492/1548492.pdf

Ioannidis, J. P. A., Cripps, S., \& Tanner, M. A. (in press). Forecasting for COVID-19 has failed. International Journal of Forecasting. Available online 25 August 2020. In Press, Corrected Proof doi.org/10.1016/j.ijforecast.2020.08.004

Luhmann, N. (2012). Introduction to systems theory (P. Gilgen, Trans.) Polity Press. (Original work published 1984).

Morse, S. S., Mazet, J. A., Woolhouse, M., Parrish, C. R., Carroll, D., Karesh, W. B., ... Daszak, P. (2012). Prediction and prevention of the next pandemic zoonosis. The Lancet, 380(9857), 1956-1965. doi.org/10.1016/S0140-6736(12)61684-5

Peters, H. P., Heinrichs, H., Jung, A., Kallfass, M., \& Petersen, I. (2008). Medialization of science as a prerequisite of its legimitization and political relevance. In D. Cheng, M. Claessens, T. Gascoigne, J. Metcalfe, B. Schiele, \& S. Shi (Eds.), Science communication in social context: New models, new practices. Springer. doi.org/10.1007/978-1-4020-8598-7_5

RKI. (2020a). Nowcasting und R-Schätzung: Schätzung der aktuellen Entwicklung der SARSCoV-2-Epidemie in Deutschland [Nowcasting and R-estimation: Estimation of the current development of the SARS-CoV-2 epidemic in Germany]. Robert Koch Institute. www. rki.de/DE/Content/InfAZ/N/Neuartiges_Coronavirus/Projekte_RKI/Nowcasting.html

RKI. (2020b). COVID-19: Fallzahlen in Deutschland und weltweit [COVID-19: Case numbers in Germany and worldwide] (Daily report). Robert Koch Institute. www.rki.de/ DE/Content/InfAZ/N/Neuartiges_Coronavirus/Fallzahlen.html 
Solomon M. (2015). Making medical knowledge. Oxford University Press.

Tretter, F. (2008). Ökologie der Person: Auf dem Weg zu einem sytemischen Menschenbild [The ecology of the Person : Toward a systemic picture of humans]. Pabst Science Publishers.

Tretter, F., Gaugler, T., Bieling, C., Tretter, C., Underberg, E., Harrer-Puchner, G., \& Franz-Balsen, A. (2020). Ein Virus verändert unser Weltverhältnis [A virus changes our relationship to the world]. GAIA, 29(2), 83-87. doi.org/10.14512/gaia.29.2.4

Tretter, F., \& Löffler-Stastka, H. (2019a). Medical knowledge integration and "systems medicine": Needs, ambitions, limitations and options. Medical Hypotheses, 133, 109386. doi.org/10.1016/j.mehy.2019.109386

Tretter, F., \& Löffler-Stastka, H. (2019b). The human ecological perspective and biopsychosocial medicine. International Journal of Environmental Research, 16, 7230. doi.org/10.3390/ijerph16214230

Tretter, F., \& Reichel, C. (2020). Humanökologie der Krisen: Systemische Annäherungen an COVID-19 (The human ecology of crises: Systemic approaches to COVID-19). GAIA, 29(4), 278-280. doi.org/10.14512/gaia.29.4.16

UNESCO. (2020). Journalism, press freedom and COVID-19 [Issue brief in series: World Trends in Freedom of Expression and Media Development]. United Nations Educational, Scientific and Cultural Organization. en.unesco.org/sites/default/files/unesco_covid_ brief_en.pdf

WCS. (2020). One planet, one health, one future. World Conservation Society. www.wcs.org/ one-planet-one-health-one-future

Wegwarth, O., Kendel, F., Tomsic, I., von Lengerke, T., \& Härter, M. (2020). Risikokommunikation unter Unsicherheit [Risk communication during uncertainty]. Kompetenznetz Public Health COVID-19. www.public-health-covid19.de/images/ 2020/Ergebnisse/Corr_20200626_Kommunikation_Handreichung_COVID_ Kommunikation_Unsicherheit_Risiken_Revision_FINAL_CLEAN.pdf

WHO. (2005). Ecosystems and human well-being: Health synthesis. World Health Organization. www.who.int/globalchange/publications/ecosystems05/en/

WHO. (2017). One health. World Health Organization. www.who.int/news-room/q-a-detail/ one-health

WHO. (2018, November 12). Of all human diseases, 60 percent originate in animals"One Health" is the only way to keep antibiotics working [News release]. World Health Organization Regional office for Europe. www.euro.who.int/en/health-topics/diseaseprevention/antimicrobial-resistance/news/news/2018/11/of-all-human-diseases,-60originate-in-animals-one-health-is-the-only-way-to-keep-antibiotics-working

WHO. (2020a). WHO Coronavirus disease (COVID-19) dashboard [Data set]. World Health Organization. Retrieved May 25, 2020, from covid19.who.int 
WHO. (2020b, April 14). COVID-19 strategy update. World Health Organization. www.who.int/docs/default-source/coronaviruse/covid-strategy-update-14april2020. pdf?sfvrsn=29da3ba0_19

WHO. (2020c, September 23). COVID-19 pandemic: Countries urged to take stronger action to stop spread of harmful information [News release]. World Health Organization. www. who.int/news/item/23-09-2020-covid-19-pandemic-countries-urged-to-take-strongeraction-to-stop-spread-of-harmful-information

WHO. (2020d). Pandemic fatigue-Reinvigorating the public to prevent COVID-19: Policy frameworkforsupportingpandemic prevention and management. World Health Organization Regional office for Europe. apps.who.int/iris/bitstream/handle/10665/335820/WHOEURO-2020-1160-40906-55390-eng.pdf

Wittgenstein, L. (1921/1981). Tractatus Logico-Philosophicus (TLP). (C. K. Ogden, trans.). Routledge \& Kegan Paul. (Original work published 1921)

Worldometer. (2020). COVID-19 Coronavirus pandemic [Data set]. Retrieved May 25, 2020, from www.worldometers.info/coronavirus/ 
This text is taken from Human Ecology Review, Volume 26, Number 1, 2020, published by ANU Press, The Australian National University, Canberra, Australia. doi.org/10.22459/HER.26.01.2020.04 